been mentioned by Dr. W. T. Berrill (13 November, p. 425) and it is well known that the prognosis for spontaneous recovery from Bell's palsy is reasonably good. Taverner and his colleagues ${ }^{1}$ in describing the natural history of Bell's palsy comment that about three-fifths of patients recover completely. They state that of the remainder, who develop degeneration of the facial nerve, about one-quarter remain permanently dissatisfied with their eventual state of recovery. Thus some $10 \%$ of patients who develop Bell's palsy may be expected to have persisting paralysis and disfigurement, often with troublesome permanent sequelae.

In an earlier paper Langworth and Taverner $^{2}$ referred to a group of 39 patients with Bell's palsy in whom partial denervation had occurred. No treatment was given, and all patients in this group, who were followed up for nine months, recovered at least $80 \%$ of normal function. Twenty-nine patients in whom complete denervation occurred were also described, and clinical recovery of the circumoral muscles varied from almost nil to $40 \%$ even in this group.

No treatment is necessary if no denervation occurs, but it is notoriously difficult or impossible by electrical tests to identify within the first few days of the palsy those cases in which nerve degeneration is developing and who might be helped by steroid therapy. From the clinical aspect, if the facial palsy is complete at the onset or within the first few days full recovery cannot be expected. Unilateral loss of taste sensibility or marked impairment of the anodal galvanic stimulation response by the anterior two-thirds of the tongue during the first 14 days of the palsy is also held to imply a bad prognosis. According to Matthews ${ }^{3}$ an absolutely good prognosis, with complete recovery, is indicated if the facial palsy remains partial within six days of the onset. As Miller has also observed: "If any voluntary movement whatever is present five days after the onset, functional recovery will be nearly perfect, even where some evidence of denervation and reinnervation remains."

Taverner and his colleagues 156 believe that in very severe attacks of Bell's palsy the major damage may be done within the first few hours and that treatment should therefore be started at once. If steroids prevent or reduce nerve degeneration, and if they must be given before such degeneration can be demonstrated, then treatment must begin when the palsy first appears. Indeed, Briggs and Potter $^{7}$ have used steroid prophylactically in injured patients who had radiological evidence of a petrous temporal fracture and a bleeding ear on the same side. An eight-day course of ACTH gel was given, the first dose being administered on the day of the injury. Without such treatment $38 \%$ of patients develop some degree of facial weakness but with steroid prophylactic therapy only $8 \%$ did so. Nevertheless, they are not convinced that such prophylactic treatment need always be adopted, since most patients who develop this complication of head injury will recover completely or to an acceptable degree from their facial weakness without treatment.

Whether the increased recovery rate which is claimed in Bell's palsy is sufficient to justify the use of full doses of prednisolone in every case may still be regarded as a controversial question. In about $80 \%$ of the patients it is unnecessary and steroid therapy still provides no guarantee of full recovery. Treatment must in any event be given at the earliest possible moment after the onset of the palsy. If persistent palsy is preventable it must be prevented, but are we to regard the immediate use of predinsolone as obligatory in all cases of Bell's palsy? I am, etc.,

ERIC C. O. JeWESBURY

Royal Northern Hospital, 1 raverner, D., Fearnley, M. E., Kemble, F., Medical Fourmal, 1966, 1, 391.
Langworth, E. P., and Taverner, D., Brain, 1963, 86, 465. P., and Taverner, D., Brain,
Matthews, W. B., British Medical foumal, 1961, 2.,215. 3, 815

5 Taverner, D., Kemble, F., and Cohen, S. B. British Medical Fournal, 1967, 4. 581 . 6 Taverner, D., Cohen, S. B., and Hutchinson, B. C., British Medical fournal, $1971,4,20$.
Briggs, M., and Potter, J. M., British Medical fournal, 1971, 3, 458 .

SIR,-Dr. W. T. Berrill in his letter (13 November, p. 425) refers to a recent pape by my colleagues and me ( 2 October, $p$. 20).

We explained that the trial we reported was designed in the expectation of showing that corticotrophin is superior to prednisolone in the management of Bell's palsy. Anticipating possible objections, we deliberately chose a dose of corticotrophin already known to be effective in this situation ${ }^{2}$ and as large a dose of prednisolone as seemed prudent yet likely to be effective. The incidence of side effects was low and is fully reported. Since completing the trial we have reduced the initial dose of prednisolone to $60 \mathrm{mg}$ daily without any apparent deterioration in our results.

We showed that prednisolone achieved better results than corticotrophin when treatment was started during the first two days after onset $(0.025>P>0.01)$. The difference in the proportions quoted by Dr. Berrill is not significant $(P>0 \cdot 10)$.

Sex has no bearing on the outcome in Bell's palsy whether treated or not. I have today examined a previous analysis of 340 patients similar to our present series and fully confirmed this statement. The details of gender were not included in our report because of their irrelevance. They are shown in the accompanying Table. None of the differences are significant $(P>0 \cdot 10)$

Sex Distribution of Patients with Bell's Palsy

\begin{tabular}{l|c|c|c|c|c}
\hline Sex & Total & $\begin{array}{c}\text { Re- } \\
\text { covered }\end{array}$ & $\begin{array}{c}\text { Dener- } \\
\text { vated }\end{array}$ & $\begin{array}{c}\text { Pred- } \\
\text { nisolone }\end{array}$ & $\begin{array}{c}\text { Cortico- } \\
\text { trophin }\end{array}$ \\
\hline Male & 97 & 73 & 24 & 42 & 55 \\
Female & 89 & 69 & 20 & 50 & 39
\end{tabular}

The reasons for exclusion of patients from the trial are fully stated. It would be an absurdity to use the results from such a heterogeneous group as a check on the validity of a fully randomized prospective controlled trial.-I am, etc.,

The General Infirmary,

D. TAVERNER

Leeds

1 Taverner, D., Cohen, S. B., Hutchinson, B. C., British Medical fournal, 1971, 4, 20. Taverner, D., Fearnley, M. E.' Kemble, F., Miles, D. W., and Peiris, Ó. A., British
Medical foumal, 1966, 1, 391.
Lead in the Community

SIR,-Recent discussions in the press and elsewhere of environmental lead problems encouraged me to read again your leading article on lead in air (18 September, p. 653). British Rail has an unfortunate inheritance of many thousands of iron and steel structures coated with lead paints for more than a century. The surface preparation of these structures for maintenance painting is costly, and our civil engineers have of necessity adopted techniques for the rapid removal of old, loose paint and corrosion residues. These methods involve burning off deposits with oxy-gas flames or removing them by mechanical abrasion. The lead hazard is obvious, and considerable effort and expense is devoted to its control.

Our search for alternatives to lead primers and surface coatings has proved remarkably successful. Non-lead paint systems totally replaced lead for the painting of rolling stock many years ago. No lead finishing coats are now used on wooden or iron and steel structures. The most intransigent problem is finding an alternative to the traditional red lead primer for new steelwork. Cautious engineers are reluctant to abandon well known methods of corrosion prevention on expensive iron and steel structures which have to last for decades. The problem has assumed added urgency because of the increasing application of the box girder, more particularly in other than railway structures.

There is an urgent need to adopt safe alternatives such as primers based on zinc phosphate. Zinc phosphate primers can be sprayed at high speed, and I am assured that subsequent coats of paint can be applied at a shorter interval after initial priming. The technical advantages are self-evident. British Rail have now decided that zinc phosphate primers will replace red lead for the treatment of all new steelwork and maintenance painting.-I am, etc.,

A. H. JONES

British Railways Board,

Marylebone Station

London N.W.1

\section{Health Care in the U.S.A.}

SIR,-I must take issue with a statement made in your leading article on "Health Care in the U.S.A." (18 September, p. 658). You stated that "The American Medical Association's Medicredit plan would provide only basic hospital and doctor care." Allow me to correct that assertion with a description of what Medicredit really does provide.

Medicredit provides comprehensive health care for all persons under age 65 through a voluntary national health insurance plan. It guards against both the ordinary and catastrophic expenses of illness. It would assure the poor of access to quality health care and help others purchase private health insurance through a sliding scale of tax credits.

Medicredit provides payment of expenses for inpatient care in a hospital or extended care facility; outpatient and emergency care; and physician's services wherever they are provided. Basic benefits in a 12-month policy period would include 60 days of inpatient hospital care, including all of the customary inpatient services such as semiprivate room staff nursing; drugs and oxygen; blood and 
plasma; and biologicals and supplies. It such events are likely to happen if it ised would also cover the use of hospital for other longer procedures or in children. facilities ordinarily furnished for the care To do so would be unjustifiably to condemn and treatment of inpatients, including the a useful drug.-We are, etc., surgery or delivery room, recovery room intensive care or coronary care units, and other rehabilitation care units. It would provide care for pregnancy and any of its complications and for psychiatric treatment. An insured individual would also be entitled to inpatient service in an extended care facility. Within the 60-day limit, two days in an extended care facility would be considered to be equivalent to one day in the hospital.

Outpatient or emergency room care would include diagnostic services, including $x$-rays, electrocardiograms, and laboratory tests; use of operating cystoscopic and cast rooms and supplies as well as emergency room and supplies.

Physicians' services would be furnished without limit when provided by or under the direction of a doctor of medicine or a doctor of osteopathy in a hospital, extended care facility, the physician's office, the patient's home, or elsewhere. Such services would consist of the diagnosis or treatment of illness, psychiatric care, well-baby care, inoculations and immunizations, physical examinations, consultations, diagnostic $x$-ray and laboratory services, radiation therapy, anaesthesiology, and services for pregnancy and any of its complications. Cosmetic surgery would be provided when necessary to correct deformities sustained through injury or illness. Additional benefits would include ambulance services, and dental or oral surgery when related to fractures of the jaw. Should basic benefits become exhausted, catastrophic protection would pay expenses for benefits in excess of the basic coverage. This would include unlimited hospital care and unlimited physician services, as well as an additional 30 days' treatment in an extended care facility, outpatient blood, and prosthetic appliances.

I think you will agree Medicredit does provide much more than basic hospital and doctor care.

I would also like to comment on your cost figure for the Kennedy plan of $\$ 41$ billion a year. According to a Social Security Administration estimate a more accurate figure would be about $\$ 77$ billion. The cost of Medicredit is estimated at about $\$ 12$ billion.-I am, etc.,

Max H. Parrott

Chicago, Ill., U.S.A. Chairman,

\section{Psychosis and Ketamine}

SIR,-Ketamine is a most valuable drug for use in certain specific circumstances, such as burns dressings, cardiac catheterization in children, and certain neuroradiological procedures. It is, however, not devoid of troublesome sequelae and should not be used routinely for operations which can be carried out under other types of anaesthesia. This includes minor gynaecological operations, and there have been ample publications, from this centre among others, ${ }^{1-3}$ to show that unpleasant side effects make it unsuitable for use in this field. Dr. B. D. Johnson's case report (13 November, p. 428) supports this view, particularly in view of the high dosage used, but it must not be taken to imply that
JOHN W. DUNDEE D. L. COPPEI

Department of Anaesthetics, Royal Victoria Hospital,

Belfast 12

1 Dundee, J. W., et al., Lancet, 1970, 1, 1370. Bovill, J. G., Clarke, R. S. J., Dundee, J. W. W.,
Pandit, S. K., and Moore, J., British fournal of
Anaesthe:sia, 1971, 43, 600.

3 Bovill, J. G., Coppel, D. L., Dundee, J. W., and Moore, J., Lancet, 1971, 1, 1285.

\section{Age and Carcinoma of the Cervix}

SIR,-The article by Dr. Sylvia W. Davies and Miss Ruth M. Kelly (27 November, p. 525) on intraepithelial carcinoma of the cervix uteri in women under 35 was most interesting, and it is almost certain that your readers would like to know that the combined Edinburgh and Newcastle figures on this same point, were presented in 1966. 1,352 cases of asymptomatic pre-invasive and microinvasive carcinomas, found from 1950 to 1965 inclusive, showed $511(37.8 \%)$ aged 35 or under and $785(58.1 \%)$ aged 40 years or under.

The case for taking cervical smears from all girls on whom a speculum examination can be justified must now be regarded as being established.-I am, etc.,

A. F. ANDERSON University of Edinburg Crooke, A. C., Butt, W. R., and Bertrand, P. V.,
Lancet, 1966, 2, 1030.

\section{Herpetic Whitlows: A Medical Risk}

SIR,-Y Your leading article "Herpetic Whitlow: A Medical Risk" (20 November, p 444) rightly points out the risk of primary herpes simplex infections in the fingers of medical students, doctors, and nurses, who because they predominantly are drawn from higher socioeconomic groups are at a disadvantage because of their low incidence of antibody to the virus. In Oxford we have studied our clinical students over many years. Over the period April 1964 to October 1968 only $32.8 \%$ of British born students had antibody.

Because of the low incidence of antibody we have had a high incidence of herpetic whitlows in the groups at risk, and as we developed various forms of treatment of cutaneous herpes with idoxuridine we have used these methods in the treatment of herpetic whitlows. The results have been published. ${ }^{1}$ Two patients treated with $0.1 \%$ idoxuridine in water administered by spray gun fared no better than Stern's untreated patients. Virus could be isolated for three weeks, the pain lasted for nine days, and the time to complete healing was about 25
Department of Obstetrics and Gynaecology,

days. A further seven patients were treated with $5 \%$ idoxuridine in dimethyl sulphoxide, applied intermittently. Pain continued for an average of 7.7 days, virus could be isolated for an average of 12.4 days, and complete healing occurred 22.1 days after the start of treatment. However, a further eight patients were treated with $40 \%$ idoxuridine in dimethyl sulphoxide and the improvement was striking: pain lasted for an average of 1.6 days, virus could be isolated for an average of seven days only, and complete healing had occurred after an average of a fortnight. We cannot recommend the treatment with intermittently applied $5 \%$ idoxuridine in dimethyl sulphoxide. Our results do not suggest any real clinical improvement, though herpes could be isolated for a shorter time. The treatment of choice at present is with continuously applied $40 \%$ idoxuridine in dimethyl sulphoxide. A piece of lint cut to cover the lesion is wetted with the substance, and in turn covered with further pieces of lint. The finger is splinted, the arm elevated, and the lint is kept damp by daily rewetting with the active fluid.

One patient was of particular interest. A physician aged 44 had by accident stuck a needle contaminated with vesicle fluid from a herpetic lesion into his right middle finger. $\mathrm{He}$ had never had herpes simplex infection in the past. On the fifth day he developed an early lesion from which virus was isolated, and this was treated with continuously aoplied $40 \%$ idoxuridine in dimethyl sulphoxide. His complement fixing antibody and neutralizing antibodv titres have been followed at reqular intervals since, and it will be seen from the Table that anart from one occasion about three weeks after the infection he has not had detectable complement fixing antibody and the neutralizing antibody titre has been extremely low. $\mathrm{He}$ is otherwise immunologically competent. Presumably so much virus was killed by the early application of the antiviral agent that only sufficient antigen was left behind to give a barelv detectable level of neutralizing antibody. None of the patients who were treated with continuously abplied idoxuridine have had recurrences of their whitlows. We usually continue treatment until virus can no longer be isolated.

The statement that herpes simplex virus does not infect by direct inoculation in people who have herpes antibody is not strictly correct. We have seen an examole of this in a young man who had a recurrent cold sore and who implanted virus into the skin of his neck (where he had never before had anv lesions) with an unfamiliar dry razor which he was lent when admitted to a ward. $\mathrm{He}$ had adequate levels of circulating antibody. Even if medical personnel know that they have antibody to herpes simplex they should still treat herpetic lesions in their patients with respect.-I am, etc.,

Radcliffe Infirmary,

B. E. JUEL-JENSEN

Oxford 1 Juel-Iensen.
College Health

\begin{tabular}{|c|c|c|c|c|c|c|c|c|c|}
\hline Date & 8.2.68 & 12.2 & 24.2 & 11.9 & 15.11 & 22.5 .69 & 3.11 & 18.7 .70 & 13.1.71 \\
\hline C.F.T. & $<1 / 4$ & $<1 / 2$ & $1: 16$ & $<1 / 4$ & $<1 / 4$ & $<1 / 4$ & $<1 / 4$ & $<1 / 4$ & $<1 / 4$ \\
\hline N.A. & $<1 / 2$ & $1 / 4$ & $1 / 4$ & $1: 2$ & $<1 / 2$ & $<1 / 2$ & $\stackrel{1: 1-\overline{1}}{<1: 2}$ & $1: 2$ & $1: 2$ \\
\hline
\end{tabular}

